\title{
AS COMUNIDADES DE FUNDO DE PASTO E O PROCESSO DE FORMAÇÃO DE TERRAS DE USO COMUM NO SEMIÁRIDO BRASILEIRO
}

\section{The fundo de pasto communities and the land common use formation process in brazilian semiarid}

Leônidas de Santana Marques

Universidade Federal de Alagoas - UFAL, Arapiraca, Alagoas, Brasil. leonidas.marques@delmiro.ufal.br

Artigo recebido em 16/05/2016 e aceito para publicação em 18/11/2016

RESUMO: O rural brasileiro caracteriza-se por uma grande diversidade de formas de territorialização camponesa, principalmente quando são consideradas as diferentes comunidades tradicionais presentes no país. Assim, o objetivo deste artigo é compreender o processo de territorialização das comunidades de Fundo de Pasto no semiárido brasileiro, mais especificamente no estado da Bahia. Para tanto, a análise considerou a construção de um breve estado da arte dos autores das ciências humanas que tem estudado estas comunidades, bem como analisa-se a processo de formação de terras de uso comum no semiárido baiano, território de reprodução social dos Fundos de Pasto. Por fim, salienta-se a relação que a produção das terras de uso comum apresenta com a formação do latifúndio no semiárido baiano.

Palavras-chave: campesinato; comunidade tradicional; territorialização; campo brasileiro.

ABSTRACT: The Brazilian rural is characterized by a peasant territorialization very diverse, especially when we consider the different traditional communities in the country. The aim of this article is to understand the territorialization process of the Fundo de Pasto communities in the Brazilian semiarid, specifically in the state of Bahia. Therefore, the analysis considers the construction of a brief state-of-the-art of authors of the humanities that has studied these communities. Moreover, the article analyzes the land common use formation process in the semiarid region, territory of social reproduction of the Fundos de Pasto. Finally, the article shows the relationship between the land common use formation process and the formation of the large property in semiarid region.

Keywords: peasantry; traditional community; territorialization; Brazilian rural. 


\section{INTRODUÇÃO}

Ao longo do século XX, vários processos transformaram de forma significativa a sociedade, tendo como uma das principais repercussões espaciais a maior interdependência global e a internacionalização do capital. Este processo materializou-se de diferentes formas no semiárido brasileiro, tanto no urbano quanto no rural. Quanto a este, um dos principais exemplos é a chamada agricultura científica que se consolidou em várias partes do país, trazendo em si uma elevada capacidade técnica que possibilita a inserção de verdadeiros pontos luminosos do agronegócio em áreas onde, principalmente por razões de natureza climática, a exploração em grandes proporções não compensava os gastos provenientes (ELIAS, 2006). Mesmo que este fenômeno possa ser apontado como um dos principais geradores de conflito pelo uso da terra, percebe-se que o semiárido brasileiro apresenta uma complexidade de capitais que se territorializam de distintos modos, gerando também diferentes formas de conflitos pelo uso da terra.

Os avanços no processo de internacionalização do capital trouxeram para o contexto do semiárido, empresas a partir da desconcentração espacial das atividades. Neste contexto, o que se presencia hoje são inúmeras empresas com capital estrangeiro (embora não necessariamente) que se apropriam do território camponês, com diversos rebatimentos nas formas de uso da terra. Assim, a partir da segunda metade do século $\mathrm{XX}$, vários conflitos surgem nesta porção do Brasil, evidenciando a complexidade do semiárido em suas formas de territorialização. Neste contexto complexo de resistência, estão as comunidades de Fundo de Pasto, fração do campesinato brasileiro que se territorializa no estado da Bahia e que ainda necessita de análises aprofundadas sobre diferentes prismas, incluindo a dimensão espacial.

Assim, o objetivo deste artigo é compreender o processo de territorialização das comunidades de Fundo de Pasto no semiárido brasileiro, mais especificamente no estado da Bahia. Ao longo do texto são apresentados elementos do processo histórico de resistência destas comunidades a partir das formas de apropriação da colônia brasileira há séculos e como estas formas se entrelaçam com a conjuntura atual da estrutura fundiária, considerando, dialeticamente, tanto o uso camponês como o latifúndio. Neste contexto, também são abordados os autores que analisam as comunidades de Fundo de Pasto, levando em conta os principais aspectos que podem ser considerados atualmente como importantes para compreender como se territorializam estes grupos, as características de sua resistência e as formas camponesas/tradicionais de se relacionar com a terra, aquilo que foi denominado por Torres (2011) como "Sistema Fundo de Pasto".

\section{O PROCESSO DE FORMAÇÃO DAS TERRAS DE USO COMUM}

Reconhecer os processos que marcaram a estruturação das comunidades de Fundo de Pasto é acompanhar os diversos desdobramentos da ocupação e colonização do semiárido brasileiro, de acordo com formas de reger e controlar a terra e mecanismos jurídicos e sociais que foram fundamentais para que, dialeticamente, se formassem tanto o latifúndio como os pequenos apossamentos camponeses. Assim, indo além daquilo que é largamente conhecido, o regime de apropriação por parte da coroa portuguesa no Brasil não se deu somente com as capitanias hereditárias e os subsequentes governos gerais. Estas formas mais amplas de gestão do território nacional foram complementadas por um modelo regional/local de divisão das terras conhecido como sesmarias. Este sistema se instituiu inicialmente em Portugal, ironicamente, como forma de dar mais aproveitamento às porções com pouca produtividade no país, com vistas aos momentos de fome da população (NEVES, 2005). Assim as sesmarias foram pensadas como mecanismo de inibição de terras ociosas no território português. Este regime de apropriação sofreu mudanças significativas no solo colonial brasileiro.

O regime de sesmarias estendeu-se ao Brasil com as capitanias hereditárias, instituidas por D. João III, em 1534. Seu conceito continuou o mesmo de Portugal, com algumas adaptações, significando terras conquistadas não ocupadas economicamente, doadas pelos capitães donatários e, mais tarde, pelos capitães governadores, com posteriores confirmações, para exploração de particulares, ou seja, território disponivel para colonização de terceiros, com 
anuência governamental. Quanto ao substantivo sesmeiro, passou a significar donatário de sesmaria, diferentemente de Portugal, onde denominava o agente do poder público, encarregado da repartição de terras por esse regime (NEVES, 2001, p. 119-120).

Neste contexto, o regime de sesmarias, que em Portugal serviu para diminuir a ociosidade da terra, se transformou na base para a consolidação do latifúndio no sertão brasileiro. A grande quantidade de terras em relação ao número de colonizadores (principalmente se for considerada esta razão com a realidade portuguesa) foi base para a instauração de um parcelamento em grandes porções, medido geralmente em léguas, em que os limites eram imprecisos, havendo geralmente uma légua de distanciamento entre uma sesmaria e outra (GARCEZ, 1987).

A pecuária bovina foi a principal atividade econômica que sustentou esta forma de apropriação. A densidade de cabeças de gado por hectare era muito pequena e o controle efetivo do rebanho era feito pela figura do vaqueiro, considerando que o proprietário (que tinha recebido o direito de usufruir aquela porção de terras) geralmente estava ausente do convívio diário. Desta forma, o gado era criado solto nas áreas de caatinga, que, naquele momento, não apresentavam qualquer forma de cercamento que impossibilitasse $o$ livre trânsito do rebanho. "A colonização foi, portanto, marcada pela concentração e a imprecisão dos limites fundiários e pelo assentamento dos proprietários a partir de investimentos reduzidos. O crescimento da produção efetuava-se pela exploração de novas terras" (SABOURIN et al, 1999, p. 91).

No cenário baiano, por meio de diversos conflitos e disputas territoriais com povos indígenas e outros ocupantes do interior, se instituíram dois grandes domínios senhoriais. Estes foram conhecidos como Casa da Ponte, pertencente à família dos Guedes de Brito, e a Casa da Torre, pertencente à família dos Garcia d'Ávila. A área de influência das duas casas ocupava a grande parte do que hoje é reconhecido como estado da Bahia. Toda a dimensão destes domínios pode ser compreendida através de alguns relatos históricos.

Sendo o sertão da Bahia tão dilatado, como temos referido, quase todo pertence a duas das principais famílias da mesma cidade, que são a da Torre, e a do defunto mestre de campo Antônio Guedes de Brito. Porque a casa da Torre tem duzentos e sessenta léguas pelo rio São Francisco, acima à mão direita, indo para o sul, e indo do dito rio para o norte chega a oitenta léguas. E os herdeiros do mestre de campo Antônio Guedes possuem desde o morro dos Chapéus até a nascença do rio das Velhas, cento e sessenta léguas. $E$ nestas terras, parte os donos delas têm currais próprios, e parte são dos que arrendam sitios delas pagando por cada sítio, que ordinariamente é de uma légua, cada ano, dez mil réis de foro (ANTONIL, 1976, p. 200).

Principalmente a partir da segunda metade do século XVII, estas duas famílias consolidaram seu poder por meio do regime de sesmarias. O relato acima de André J. Antonil, que data originalmente de 1711, aponta para a grandiosidade destas casas, que corresponderiam hoje a distintos municípios do semiárido baiano. Toda esta discussão, contudo, se vale para o reconhecimento dos processos que dão base à formação das comunidades de Fundo de Pasto no semiárido baiano. Para tanto, destaca-se o último trecho da citação de Antonil, quando se refere às formas complementares de ocupação do território que se faziam através de arrendamentos que eram pagos em foros de dez mil réis. A figura do foreiro (aquele que paga o foro) é central para compreensão desta estrutura fundiária, levando em conta como as relações entre este, geralmente associado aos vaqueiros, e o sesmeiro se desenvolveram dando condições para que os domínios permanecessem. Ao mesmo tempo em que ao foreiro era exigido o trabalho para manutenção do gado bovino, central para o abastecimento da porção litorânea da colônia, era permitida a criação de pequenos animais de propriedade do vaqueiro e sua família. Foi por meio desta relação que vários grupos camponeses começaram a se instalar no semiárido, dando condições para o desenvolvimento do latifúndio através do seu trabalho ao mesmo tempo em que se reproduziam enquanto camponês.

Além da possibilidade de criação de animais de pequeno porte, geralmente caprinos e ovinos, era direito do vaqueiro a retenção de parte do rebanho bovino em 
tempo de recria, em formas conhecidas como "sorte" ou "quarta", nas quais o trabalhador era pago com um em cada quatro animais nascidos, o que deu condições básicas de reprodução destes sujeitos mesmo depois do fim do regime de sesmarias (FERRARO JR, 2008). A própria organização espacial dos apossamentos senhoriais, que separavam cada rebanho com uma distância de algo entorno de uma légua, deu condições para a instituição de áreas sem controle direto e uso por parte dos sesmeiros, dando base material para o desenvolvimento dos rebanhos marginais.

Como discutido por Santos (2010), havia um pacto entre as duas casas para que não houvesse disputas territoriais entre os dois domínios. O objetivo básico das casas era exatamente desenvolver uma rede de relações entre o senhor e os foreiros, constituição de uma trama de poder que conferia renome e status para os representantes das famílias Guedes de Brito e Garcia d'Ávila. Desta forma, embora estivesse presente o rebanho bovino dos senhores que abastecia as maiores cidades do litoral, pouco a pouco, os foreiros foram ganhando maior autonomia no seu apossamento, que apresentaria mudanças qualitativas importantes com a dissolução do regime de sesmarias.

O apoio dos d'Ávila ao império português na dizimação de povos indígenas e no período da invasão holandesa thes conferiram grande prestígio e renome na sede da colônia e em Portugal, contexto que foi marcado por mais doações de sesmarias sertão a dentro (SANTOS, 2010). E assim foi se instituindo o poder da Casa da Torre ao longo das décadas, baseado no sistema de sesmarias. Esta problemática foi levantada algumas vezes por Cartas Régias da coroa, que pretendiam reduzir o tamanho de algumas sesmarias e incentivar uma maior produtividade das mesmas, considerando a possibilidade de demarcação; estas indicações, contudo, eram pouco consideradas pelos grandes senhores de terra.

A Coroa, por sua vez, era refém do poderio de senhores como os d'Ávila, já que esses sempre foram agraciados com patentes militares, mercês reais, honrarias religiosas, e, nos "sertões" do Nordeste, eram não somente representantes do Estado, mas, na prática, eram o próprio Estado Colonial personificado, exercendo seu poderio à base da força com o uso de sua pode- rosa Ordenança composta de índios, mestiços e escravos (SANTOS, 2010, p. 49).

Assim, além de prestígio, as Casas da Torre e da Ponte representavam a própria estabilidade do comando português nas áreas interioranas da colônia. O Estado se fazia presente por meio desta forma histórica de ocupação e qualquer forma de interferência nesta lógica de domínio poderia ter consequências mais intensas no controle colonial. Assim, não foram interferências da metrópole que fizeram ruir o poder instituído pelas Casas, mas problemáticas internas que culminaram com um contexto de mudanças na conjuntura da colônia no século XIX.

O poder da Casa da Torre começa a se fragilizar quando o abastecimento das vilas e cidades baianas perde centralidade na economia local, com a ascensão de novos povoamentos vinculados à extração de diamante e ouro nas Minas Gerais. Ocorre, neste sentido, um franco processo de desvalorização da terra voltada para a pecuária no semiárido baiano. A isto se soma uma série de problemas relacionados ao parcelamento da terra com foreiros, arrendatários e rendeiros. Estes se viam distantes do cotidiano de controle da Casa e cada vez mais deixavam de contribuir, do ponto de vista pecuniário, com a família que representava o poder regional. A Casa da Torre fragmentou-se em 1852 (mais de três séculos depois), com o falecimento de Antônio Joaquim Pires de Carvalho e Albuquerque - o Visconde da Torre, tendo o domínio territorial (e as dívidas) dividido entre alguns herdeiros, embora parte das terras já estivesse ocupada por posseiros ou fosse composta por alguns povoados que tinham uma dinâmica própria (SANTOS, 2010).

Diante disto nota-se que o fim oficial da Casa da Torre ocorreu alguns anos depois do fim do período colonial (1822). Sem embargo, é preciso considerar que o processo de fragmentação deste domínio já se iniciava há algumas décadas e formas próprias de poder local se instituíam nos diversos povoados e demais aglomerações do semiárido baiano. Muitas terras foram abandonadas ao longo do século XIX, o que deu base para a formação de uma estrutura fundiária diferenciada através da apropriação de vaqueiros e outros trabalhadores que não migraram com a crise econômica que fragilizou os grandes latifúndios 
pecuaristas. A isto, se soma o fim oficial do regime das sesmarias ocorrido em 1822, com a ruptura do governo português para com a colônia brasileira; neste contexto constituiu-se um vazio normativo, posto que a primeira lei sobre a propriedade da terra no país só seria definida em 1850 (TORRES, 2011). Assim, vários podem ser os fatores que deram condições para a existência das comunidades de Fundo de Pasto em seu modelo de apropriação de terras comuns.

As fazendas que resultaram dessa fragmentação-por herança, por compra, por aforamento ou outro qualquer título - sofrem a imprecisão de limites dos domínios primitivos das duas grandes Casas. O caráter extensivo da pecuária outro fator de fluidez dessas extremas. A chamada "fronteira do gado solto" jamais foi demarcada. E as terras passaram, assim indefinidas, a mãos talvez mais experimentadas nos tratos agrícolas do que nas práticas forenses. Os trâmites legais capazes de assegurar a legitimidade da posse, em geral, jamais foram cumpridos (GARCEZ, 1987, p. 30).

Toda esta imprecisão nas delimitações das posses, que se refletia diretamente nos títulos representativos das mesmas, é ainda hoje fator presente no cotidiano das comunidades de Fundo de Pasto. Na verdade, não somente destas, mas também de boa parte das grilagens que ameaçam a reprodução destes camponeses. São vários os casos de comunidades que tiveram suas terras griladas por conta de uma pessoa que se utilizou de um título de pouca precisão para afirmar que determinada porção de um município a pertencia, como no caso de documentos que afirmam que certo sujeito tem "dois mil contos de réis" em terras, sem maiores especificações.

Com relação ao período histórico discutido aqui, meados do século XIX, percebia-se que além da imprecisão nas posses reconhecidas, havia várias porções que não tinham qualquer apossamento. Em todos os dois casos a criação do bode solto favoreceu a apropriação de fronteiras de uso comum entre diversos membros de uma ou mais comunidades. Como afirma Angelina Garcez, os diversos fatores históricos, climáticos e legais foram centrais para que a exploração comunitária da terra fosse a melhor "relação necessária do homem com o meio" (1987, p. 34), isto por que o próprio regime climático do semiárido, caracterizado pela irregularidade nas precipitações, é fator central para que os camponeses tenham na caatinga uma reserva forrageira importante para a manutenção do rebanho.

Sobre a formação das terras de uso comum no semiárido baiano, Cirlene Santos afirma que essas

[...] não podiam ser vendidas, eram espaços de trabalho, de manejo do gado. Porém, o seu uso comum ocorria não somente nessas faixas divisórias entre as sesmarias. Em alguns casos, esse modo de vida estabeleceu-se anteriormente à doação da sesmaria, ou seja, como uma prática pré-existente, pois já havia posse e o uso comum da terra por diferentes grupos sociais que habitavam o sertão colonial à revelia das leis que regulavam o seu acesso. A sesmaria se sobrepunha formalmente à posse no que se refere à legalização da doação da terra, contudo, não conseguia desestruturar o modo de vida já existente (2010, p. 57).

Neste sentido, da mesma forma que hoje se presencia uma sobreposição de territorizalizações quando se considera que em uma mesma porção do espaço apropriam-se comunidades tradicionais (territorialização em nível local, com normatizações específicas, a exemplo dos direitos consuetudinários) e o Estado (territorialização em níveis mais amplos, doutrinando e regendo por meio de mecanismos mais gerais como a ação do judiciário e a implementação de uma política pública), identifica-se algo semelhante no século XIX e anteriores. Ao mesmo tempo em que o Estado de então arquitetava um modelo de normatização do território, seja o regime de sesmarias ou a Lei de Terras de 1850, as comunidades localmente apresentavam formas próprias de parcelar e apropriar-se da terra. E é neste contexto que existem condições para a formação das terras comuns. Assim como hoje as diversas formas de territorialização das comunidades tradicionais são "invisíveis" aos olhos do Estado, as terras de uso comum eram tão invisíveis quanto para o regime de sesmarias.

Do ponto de vista de marco histórico, alguns autores (DIAMANTINO, 2007; TORRES, 2011) fri- 
sam um período histórico em que não ocorreu qualquer normatização sobre a posse da terra: o fim do período colonial (1822) e a instituição da Lei de Terras (1850). Durante estes vinte e oito anos, conhecidos como período de livre apossamento, a ausência de regulação sobre a propriedade da terra foi um outro fator importante para que não ocorressem os cercamentos das terras comunais. Todas estas áreas tornaram-se devolutas a partir da Lei de Terras de 1850. É claro que não se pode identificar somente estes vinte e oito anos como o momento exato do surgimento das comunidades, posto que, como vem sendo colocado, os processos que foram centrais para a formação dos Fundos de Pasto se desenrolam ao longo de vários séculos. Neste sentido, dialeticamente, as condições que deram base para a formação do latifúndio no semiárido foram as mesmas que possibilitaram a formação destas comunidades camponesas.

\section{[...] a fronteira do gado solto se bifurcou numa economia criatória vertida principalmente para abastecer os engenhos e que permane- ce juntando seus escombros no domínio do "progresso" e uma economia de subsistência, desenvolvida à margem do latifúndio e de certo modo a eles subordinada social e politicamen- te. É nesta economia de subsistência, sempre atualizável, que se inscrevem as condições socioambientais, políticas e jurídicas que dão vazão à existência e ressignificação das terras soltas e à articulação solidária de usos e cos- tumes sobre elas (DIAMANTINO, 2007, p. 34).}

Assim, a realidade concreta na qual se implementa a Lei de Terras de 1850 é de uma sociedade marcada tanto pelo latifúndio como por pequenos apossamentos camponeses. É ainda neste contexto que surgem as chamadas "terras devolutas", que, ao invés de apresentarem uma definição clara, delimita-se segundo aquilo que não pode ser considerado como terra devoluta (TORRES, 2011). Toda a terra que não apresentava qualquer comprovação oficial de propriedade (pública ou privada) foi reconhecida por este conceito e foi incorporada aos domínios do Estado brasileiro. Neste âmbito, é possível dizer que as áreas onde se territorializam as comunidades de Fundo de Pasto são devolutas do ponto de vista do Estado, mesmo que tenham usos e formas de apropriação as mais diversas

Todas estas condições, contudo, não seriam suficientes se as áreas onde se territorializaram os Fundos de Pasto estivessem diante de uma intensa conjuntura de valoração fundiária. "A pouca pressão fundiária entre 1800 e 1920 favoreceu a consolidação das comunidades pastoris, regidas pelo direito costumeiro, no qual o conceito de posse era igual ao de domínio (FERRARO JR; BURSZTYN, 2008, s/p)". Na verdade, como dito por Sabourin et al (1999), o sistema Fundo de Pasto tinha uma abrangência ainda maior da que tem hoje e se desagregou em várias partes do estado da Bahia por diversos motivos ao longo do século XX. Isto, sem embargo, não retira a dimensão da resistência destas comunidades, que persistiram, e persistem, em distintos conflitos territoriais.

\section{A TERRITORIALIZAÇÃO DO "SISTEMA FUN- DO DE PASTO"}

Até recentemente, a bibliografia que discutia as formas como as comunidades de Fundo de Pasto se organizavam e territorializavam no estado da Bahia era bastante escassa, principalmente na Geografia. Nos últimos anos, pesquisadores de diferentes campos do conhecimento (Sociologia, Antropologia, Geografia, Direito etc.) empreenderam análises diversas sobre estas comunidades que hoje se refletem em toda uma gama de conceitos e definições envolvidas com a questão dos Fundos de Pasto. Várias são as interpretações para o porquê da permanência destas comunidades (como se o desaparecimento fosse algo inevitável!) considerando as características gerais deste modo distinto de se relacionar com a terra.

Neste contexto, vale ressaltar os primeiros escritos sobre estas comunidades, desenvolvidos ainda na década de 1980 a partir do corpo profissional da Companhia de Desenvolvimento e Ação Regional (CAR) e do já extinto Instituto de Terras da Bahia (INTERBA, que é análogo a atual Coordenação de Desenvolvimento Agrário - CDA). Nestes trabalhos, dava-se muita ênfase na forma diferenciada como os sertanejos se relacionavam com a terra e como aquele modo de vida sui generis era a única forma encontrada de sobreviver em ambiente tão inóspito. O sistema

Soc. \& Nat., Uberlândia, 28 (3): 347-359, set/dez/2016 
Fundo de Pasto é tido como secular, considerando os estudos apresentados anteriormente sobre as casas da Torre e da Ponte, frisando-se sempre o princípio comum da unicidade comunitária como algo central para a sobrevivência e reprodução dos sujeitos. Neste âmbito, o conceito mais clássico de comunidade de Fundo de Pasto é o de Angelina Garcez (1987, p. 21), uma das responsáveis pela equipe técnica da CAR.

Correspondendo à figura jurídica do "Compascuo", são comumente denominadas Fundo de Pasto as propriedade coletivas ocupadas, de modo geral, por uma comunidade de origem familiar comum, onde se realiza, como atividade predominante, um pastoreio comunitário extensivo de gado de pequeno porte e, subsidiariamente, uma precária agricultura de subsistência, representada, principalmente, pelos cultivos do milho, do feijão e da mandioca.

Esta noção de compascuo é muito presente neste texto, acredita-se, por ser uma tentativa de enquadrar a forma distinta de uso da terra com algo próximo do que era apresentado nos códigos e regramentos brasileiros. Atualmente, sabe-se que pouca efetividade, do ponto de vista da regularização fundiária, tem esta noção e o central mesmo é buscar uma normatização diferenciada para estas comunidades, conforme reafirmado nos encontros da Articulação Estadual e da Central das Associações de Fundos de Fechos de Pasto de Senhor do Bonfim - CAFFP. Outro fator que cabe mencionar é esta intensidade dada à relação sociedade-natureza, colocando a caatinga como ambiente hostil e inóspito, que tem sido problematizado nos últimos anos a partir das organizações da sociedade civil que, ao invés de encarar a problemática da seca com algo a ser combatido, tem difundido práticas de convivência com a seca.

Alguns elementos importantes que são colocados no texto de Garcez (1987) são as diversas atividades complementares à ovinocaprinocultura extensiva, como a pecuária bovina, a criação de porcos e galinhas, as lavouras de sequeiro e as próprias atividades extrativistas, como a caça. Isto tende a variar de comunidade para comunidade, de acordo com as formas como os sujeitos foram se organizando e se apropriando das terras. Cabe ainda mencionar dois pontos interessantes nesta publicação. O primeiro é a indefinição jurídica quanto a propriedade das comunidades de Fundo de Pasto, que tem se desdobrado em diversos conflitos entre camponeses e grileiros pelo direito a permanecer na terra. Esta situação não se alterou mais de vinte e cinco anos depois, posto que várias comunidades ainda não têm o título da terra garantido. $\mathrm{O}$ segundo ponto interessante do trabalho é a forma alargada que se utiliza a definição de comunidades de Fundo de Pasto, "compreendendo o conceito tanto a base física quanto a comunidade que a ocupa e o tipo de 'tenência' da terra que caracteriza essa ocupação" (GARCEZ, 1987, p. 38). Isto se reafirma nos próprios documentos das entidades representativas das comunidades, posto que não basta inferir que o fundo de pasto se limita a área de terras comuns, mas a todo o modo como as pessoas se relacionam com a terra, incluindo aí desde o apossamento individual até as relações de compadrio.

Outra conceituação interessante para as comunidades de Fundo de Pasto foi elaborada duas décadas depois por Pedro Diamantino (2007), considerando que poucos trabalhos foram construídos durante estes vinte anos. Para este autor,

Um dos traços mais marcantes das comunidades de Fundo de Pasto refere-se a mecanismos institucionais de acesso e uso das terras e pastagens nativas criadas a partir de combinações discursivas e consuetudinárias de regras de uso e de hospitalidade, reforçadas em situações de adversidades e pressão exercida sobre o grupo, regendo princípios de utilidade vital e organização sócio-cultural compartilhadas (DIAMANTINO, 2007, p. 9).

Diante desta afirmação, é possível levantar alguns elementos para compreensão dos mecanismos de reprodução social destas comunidades. O primeiro é a forma de regramento estabelecida no interior da comunidade, transmitida geralmente de modo oral e a partir de princípios consuetudinários. Esta lógica esbarra nas instituições formais do Estado, principalmente na forma de conceber as relações jurídicas da propriedade privada. Até mesmo em alguns pro- 
cessos judiciais que analisam a pertinência ou não da existência de uma comunidade de Fundo de Pasto em determinado local, foi identificado o modo como, por exemplo, o juiz faz a vistoria e nega acreditar que uma porção de vários hectares de caatinga em pé é utilizada produtivamente por um grupo de pessoas. Outro elemento interessante é a compreensão de como se instituem estes direitos consuetudinários, por meio da utilidade vital e a organização sócio-cultural compartilhada. Neste sentido, cabe mencionar que o sistema Fundo de Pasto se estabelece não por uma intencionalidade coletiva de definição de uma área de utilização comunitária, mas através de regime de uso comum das terras que se desenvolve de acordo com a utilidade daquela porção do espaço para sobrevivência dos rebanhos de ovinos e caprinos e, por conseguinte, da própria família camponesa. Esta discussão vai no sentido de se distanciar de qualquer visão mistificada das comunidades tradicionais, incluindo os Fundos de Pasto, percebendo a formação das terras comuns como algo central para a reprodução dos sujeitos em suas relações com o meio ambiente, material e imaterialmente. Assim, do ponto de vista conceitual, compreende-se que é mais acertado utilizar as expressões terras de uso comum ou terras comuns do que terras de uso coletivo ou terras coletivas.

Perceber o motivo pelo qual as comunidades de Fundo de Pasto se formaram no semiárido brasileiro é algo central. Não obstante, é fundamental também refletir sobre os processos que levaram à persistência destas comunidades, considerando que apresentam formas de apropriar-se da terra e de instituir território diferenciadas da forma como se organiza o capital agrário e algumas formas mais presentes de economia camponesa. Ferraro Jr. (2008) analisou possíveis razões para a permanência destas comunidades, considerando o fim dos currais das casas da Torre e da Ponte; estas, contudo, não são excludentes entre si e possibilitam uma análise multidimensional do fenômeno.

A primeira razão é a "ambiental", que considera que as configurações do ambiente semiárido são um fator importante na forma como a sociedade local passa a se relacionar com a natureza. Neste caso, a problemática do regime pluvial associada à baixa densidade populacional conduziu a formas de exploração extensivas e sobrepostas. Assim, como relatado anteriormente, o sistema Fundo de Pasto seria a forma mais apropriada de sobrevivência no semiárido. "Esta forma seria mais preservadora, mais econômica, mais estável e resistente" à instabilidade própria do regime climático semiárido, considerando também que o "mesmo se aplica ao desenvolvimento do bode denominado 'pé-duro', adaptado às condições de pastoreio solto na caatinga" (FERRARO JR, 2008, p. 53).

Com relação às origens culturais, o autor apresenta outras três razões. Uma é a "ibérica", considerando que na raiz cultural das comunidades, associada a uma matriz predominantemente portuguesa e/ou espanhola, está presente a forma de apropriação denominada de "baldios", que são áreas de terra livre disponíveis para o campesinato. Assim, quando alguns foreiros vieram de Portugal ocupar o semiárido brasileiro, já tinham a tradição de ocupar porções do território por meio do uso comum do solo. Neste âmbito, outra razão seria a "anti-europeia", colocando que no processo de formação populacional destas comunidades foram fortes os traços dos habitantes nativos (indígenas) e dos povos de origem africana. Estas duas matrizes traziam em sua cultura tradições comunitárias e de solidariedade, posto que "a noção de propriedade privada era estranha aos não-brancos" (FERRARO JR, 2008, p. 54). Somada a estas duas razões, o autor aponta ainda uma terceira denominada de "indígena", na qual as terras de uso comum seriam um desdobramento das porções de terra que já eram utilizadas para caça das aldeias nativas. Este trato de uso comum teria sido reforçado pelo papel missionário da Igreja utilizando-se dos princípios cristãos.

Ainda são apresentadas outras três razões de permanência e persistência das comunidades de Fundo de Pasto, são elas: "socioeconômica", "falta de ordenamento fundiário" e "clânica". No caso da primeira, $o$ autor coloca que os locais onde se desenvolveram as comunidades seriam áreas de menor interesse (baixo potencial produtivo e baixa valorização econômica) para que fossem apropriadas por outras formas de uso. Assim, a condição de "esquecimento" deu base a uma vida baseada na partilha e em relações comunitárias. Quanto à razão fundiária, Ferraro Jr. (2008) menciona que o não reconhecimento por parte do Estado, utilizando mecanismos como a regularização e titulação da propriedade, teve como reflexo o não parcelamento das 
áreas de uso comum. A esta noção vincula-se a ideia de que, para os camponeses, a terra não era de fato deles, mas dos sesmeiros (e congêneres) que as abandonaram por determinado tempo e que poderiam reclamar a propriedade a qualquer momento. Desta forma, após "a decadência dos currais (1750-1850), os vaqueiros e posseiros não se fizeram donos, supondo-se apenas usufruturários da terra e, portanto, sem direito à apropriação individual da mesma" (FERRARO JR, 2008, p. 54). A sétima razão apresentada pelo autor é a "clânica", que considera que o isolamento dos grupos que ocupavam os sertões, a maior parte deles formada por um mesmo tronco familiar, criou condições para o não parcelamento. Ou seja, as áreas de pastoreio não foram divididas por que se tratavam de pessoas com consanguinidade tal que a divisão se fazia desnecessária.

Dentre as razões explicativas, a explicação clânica (sociocultural) parece dominante frente às observações de campo. As outras estão, em geral, subordinadas a ela. A manutenção das terras indivisas só aconteceu porque os conflitos internos eram (e continuam sendo) passiveis de solução no âmbito comunitário-familiar, as comunidades são predominantemente formadas por herdeiros e seus descendentes, parentes em diferentes graus. As razões ambientais, econômicas e fundiárias também são factíveis, podendo, em diferentes graus, ter se somado para fortalecer o modo FP de uso e ocupação. As hipóteses de cunho étnico-cultural (indígenas $e$ anti-européias) são mais dificeis de avaliar e não parecem muito significativas por duas razões, primeira aquela apontada por Darcy Ribeiro quanto a não-assimilação, mas sim enfrentamento dos índios pelos vaqueiros, e a segunda razão reside no fato de a configuração aberta dos grandes currais não ter sido opção das comunidades ou dos vaqueiros, mas uma contingência das sesmarias. De qualquer modo, pode se agregar à explicação a ascendência ser de camponeses pobres, sejam portugueses, indigenas ou negros. Estes, independente de uma influência cultural direta, nunca tiveram propriedade privada de terras e não conseguiram mudar isso (FERRARO JR, 2008, p. 55).
Como explicita o próprio autor, escolher apenas uma razão para a permanência/persistência das comunidades de Fundo de Pasto no sertão baiano é restringir algo que essencialmente é plurideterminado. Neste sentindo, talvez seja ainda importante indicar uma outra razão que, embora não esteja presente (pelo menos aparentemente) nas décadas anteriores aos meados do século XX, foi central nas últimas décadas: a questão do conflito. A persistência e a permanência destas comunidades têm muito a ver com resistência, com disputas territoriais que se deram nos últimos anos e foram cruciais para que, atualmente, a situação das regularizações fundiárias esteja mais estável em algumas porções do estado da Bahia.

Considerando elementos de análise marxista da questão das relações sociais em sua reprodução, Cirlene Santos (2010) também conceitua as comunidades de Fundo de Pasto. Este trabalho traz elementos da territorialização destas comunidades no estado da Bahia, levando em conta as terras de uso comum enquanto funcionalidade para o modo camponês de apropriação. Para a autora,

\section{[...] o fundo de pasto constitui-se enquanto um} modo de vida camponês baseado em uma economia doméstica, cujo "padrão tecnológico" está fundamentado na utilização de técnicas e instrumentos rudimentares de trabalho. Os camponeses têm como valores basilares a familia, a terra e o trabalho e utilizam-se de uma incipiente agricultura e de atividades extrativas voltadas ao autoconsumo e, principalmente, utilizam-se da prática do pastoreio extensivo, compartilhado de caprinos e ovinos, em terras de uso comum, de grandes extensões, localizadas no semi-árido baiano, como mecanismo estratégico de reprodução social do grupo (SANTOS, 2010, p. 80).

Quanto às relações sociedade-natureza presentes nas comunidades, a autora aponta para algo central que é a instituição do uso comum das terras considerando a maximização do aproveitamento implementado pelo pastoreio livre da ovinocaprinocultura. Neste âmbito, é equivocado pensar que as áreas de caatinga em pé presentes nas terras comuns dos Fundos de Pasto se associam a interesses preservacio- 
nistas, como apontado por pesquisadores que refletem de forma mistificada o uso tradicional da terra. A vegetação conservada nestas áreas camponesas tem a ver diretamente com o modo de vida ali instituído, que necessita que a caatinga sirva de banco natural de forragem para alimento dos rebanhos. A relação imbricada entre sociedade e natureza neste caso aponta para uma forma de territorialização em que a ausência das reservas vegetais simplesmente não se afirma enquanto vantagem ou mesmo condição possível de sobrevivência dos Fundos de Pasto.

Um outro elemento a ser relevado que é levantado por Santos (2010), bem como pelos demais autores já colocados, é a instituição de formas solidárias de ajuda mútua, principalmente o mutirão, o batalhão e os agrupamentos de trabalho. Para a autora, as próprias condições de adversidade do ambiente semiárido deram condições para que as interdependências entre os sujeitos e o sentimento de territorialidade estivessem muito presentes no cotidiano das comunidades.

Neste contexto, utilizando-se de outros estudos que tentaram identificar comunidades rurais enquanto camponeses, Santos (2010, p. 86-87) analisou as comunidades de Fundo de Pasto e elencou alguns dos principais elementos que as caracterizam como tal:

1. Força de trabalho familiar, sendo a família o centro da unidade de produção e consumo;

2. Ajuda mútua por meio de regimes de mutirão;

3. Trabalho acessório e jornada de trabalho assalariada, identificada através de processos migratórios no período de seca, além da presença de contratação de diaristas;

4. Socialização, processo presente como forma de reprodução da própria comunidade na lida com a terra, reforçando neste caso a centralidade do trabalho para reprodução social do grupo;

5. Posse da terra, no sentido de apropriação das terras devolutas, ocorrendo nos últimos anos um processo de regularização fundiária;

6. Propriedade dos meios de produção, vinculada aos instrumentos diretamente relacionados à forma de lidar com a terra; e
7. Jornada de trabalho livre, que se caracteriza por diversas atividades, inclusive a pecuária, realizadas ao longo do dia.

Considerando os levantamentos feitos em campo, além destas características, soma-se a questão da religiosidade, que se apresenta como um traço cultural muito forte. É necessário inserir ainda outros elementos do conflito pela permanência na terra, algo fundamental para compreender a questão do ser camponês nas comunidades de Fundo de Pasto. Conforme relato de alguns sujeitos que trabalham com assessoria popular nestas comunidades, é nítido que, em momentos de maior estabilidade jurídica, alguns grupos tendem a se fragmentar e fragilizar a própria estrutura das áreas de uso comum (com alguma forma de parcelamento). Este processo, contudo, é menos evidente em comunidades que apresentam maior solidez associativa e/ou lideranças que conseguem agregar os camponeses em torno de uma pauta específica.

Para uma compreensão mais abrangente da complexidade dos Fundos de Pasto nos dias atuais, Torres (2011) considera que ocorreram mudanças qualitativas significativas a partir da segunda metade do século XX, principalmente com uma intervenção mais forte do Estado na realidade agrária das comunidades. Assim, considerando o contexto de séculos atrás,

\section{[...] era ao mesmo tempo sistema produtivo e de relações sociais, econômicas, culturais e familiares que em algumas áreas datavam de duzentos, trezentos anos, o que passou a ser conhecido como "sistema fundo de pas- to" que, a partir da década de 1980, sofreu a intervenção do Estado através do que foi denominado por este de "projeto de fundo de pasto", visando a regularização fundiária dessas áreas (TORRES, 2011, p. 50).}

Neste sentido, não é possível compreender atualmente a territorialização dos Fundos de Pasto sem considerar a sua relação com o Estado nas últimas décadas. As diversas formas de intervenção foram (e tem sido) funcionais para a organização das comunidades em associações, em nível local ou regional, que mudaram as estratégias do movimento e

Soc. \& Nat., Uberlândia, 28 (3): 347-359, set/dez/2016 
se estruturaram em uma rede espessa de sujeitos que resistem no estado da Bahia.

Neste trabalho, o autor também traz os elementos que foram considerados pelos órgãos públicos nos anos da década de 1980, e que serviram de base para a interpretação dominante sobre o que é este sistema de uso comum de terras. São estes:

$a$ - as ocupações dos fundos de pastos se dão a partir de heranças, sendo o laço familiar determinante para o ingresso na comunidade; $b$ - a estrutura familiar persiste até hoje bem como a forma tradicional de relacionamento, "contribuindo para consolidar a identidade desse grupo social";

$c$ - as áreas do criatório comum são maiores que as áreas de moradia e cultivo, não havendo divisão entre elas;

$d$ - muitas vezes as áreas de fundos de pastos se limitam com outras áreas comunitárias, sem que haja problemas de limites;

$e$ - A conformação espacial dos fundos de pastos imprime um caráter particular a essas áreas. Constitui-se de grandes extensões de terras de caatinga, mais ou menos delimitadas sem entretanto serem cercadas, onde cada uma das familias, integrantes do grupo comunitário, possui uma casa e uma área cercada para a pequena produção agrícola, sendo o restante das terras, usadas comunitariamente para o pastoreio e atividades extrativas.

$f$ - Atualmente estima-se que 5.000 familias vivam nestas comunidades (CAR, 1987 apud TORRES, 2011, p. 51-52).

Dos elementos que foram colocados nestes dados da Companhia de Desenvolvimento e Ação Regional (CAR), vale ponderar duas coisas: a primeira é o pequeno número de famílias que é apresentado (5.000), considerando que se sabe atualmente que este valor é superior em mais de quatro vezes (ainda sem considerar que outras tantas comunidades que apresentam este sistema de uso das terras não se reconheceram como tal); a segunda questão é a do cercamento, posto que no período dos primeiros trabalhos dos órgãos do Estado ainda eram mínimas as cercas, processo que se intensificou principalmente por conta da ameaça de grilagem das terras. Para além destes equívocos de revisão da realidade atual das comunidades, vale ponderar um fator importante que é apresentado no item "e" da citação acima. Quando se menciona o termo Fundo de Pasto é preciso ter em mente que não está restringindo-se às áreas de uso comum, às porções de trânsito livre dos distintos rebanhos familiares. Fundo de Pasto é muito mais do que isso, representando todo o modo de vida e territorialização camponesa correlata. Assim, as moradias, os quintais e os cercados menores são também Fundo de Pasto, bem como a sede da associação, o cemitério e as vias de acesso à comunidade. Esta visão alargada é defendida pelos próprios membros das comunidades através da Articulação Estadual dos Fundos e Fechos de Pasto em um dos seus principais documentos-síntese (ARTICULAÇÃO, 2003), e pode ser facilmente constatada em uma visita a uma área assim denominada. Não há como existir qualquer porção apropriada pelo uso comum sem que ocorra também as demais formas de organização comunitária.

No campo da Geografia, várias contribuições importantes para compreensão da estrutura agrária baiana vêm sendo elaboradas pelo Projeto GEOGRAFAR da Universidade Federal da Bahia. Especificamente quanto às comunidades de Fundos e Fechos de Pasto, existe uma série de levantamentos e sistematizações elaboradas por Denilson M. de Alcântara e Guiomar Germani. Com relação ao conceito, coloca-se que:

\section{[...] pode-se entender o Fundo de Pasto como} uma experiência de apropriação de território típico do semi-árido baiano caracterizado pelo criatório de animais em terras de uso comum, articulado com as áreas denominadas de lotes individuais. Os grupos que compõem esta modalidade de uso da terra criam bodes, ovelhas ou gado na área comunal, cultivam lavouras de subsistência nas áreas individuais e praticam o extrativismo vegetal nas áreas de refrigério e de uso comum. São pastores, lavradores e extrativistas. São comunidades tradicionais, regulamentados internamente pelo direito consuetudinário, ligados por 
laços de sangue (parentesco) ou de aliança (compadrio) formando pequenas comunidades espalhadas pelo semi-árido baiano (ALCANTARA; GERMANI, 2009, p. 13-14).

Nesta definição, como aponta o próprio título do texto, o conceito está sempre em movimento e nunca como algo estanque. Percebe-se o entendimento alargado dos autores ao inserir elementos outros que não só as terras apropriadas de forma comum, mesmo sendo este um dos crivos para o reconhecimento desta como uma comunidade tradicional. Analisando os Fundos de Pasto segundo as categorias analíticas da Geografia, Alcântara e Germani (2010) consideram que é indispensável analisar o contexto das comunidades em sua relação com os processos mais gerais da sociedade, posto que elas estão inseridas no espaço geográfico e se territorializam neste. Isto, contudo, não desconsidera que estes sujeitos são historicamente alijados da análise histórica e espacial hegemônica, por representarem formas marginais de economia.

No mesmo sentido, vale ressaltar que a compreensão das comunidades atualmente se imbrica com a própria concepção de identidade. Sem embargo, esta não pode ser vista como uma identidade calcada em costumes e rotinas abstratas, desvinculadas do cotidiano camponês e associadas às derivações individuais de cada sujeito. Quanto às comunidades de Fundo de Pasto, o que se exprime é uma identidade eminentemente política, "marcada pelo sujeito histórico que alimenta e põe em evidência o sujeito de direito" (ALCÂNTARA; GERMANI, 2010, p. 43). Ao longo das décadas da segunda metade do século XX e início do XXI, as comunidades vêm produzindo e retrabalhando sua identidade por meio do conflito e da relação com o Estado e os agentes do capital.

Vale ainda colocar alguns pontos que ajudam no entendimento destas comunidades. Primeiramente, é preciso considerar as diferenças existentes entre os Fundos de Pasto e os Fechos de Pasto ou Fechos do Oeste. Estas duas formas de comunidades camponesas tradicionais apresentam semelhanças, principalmente quanto ao uso comum das terras para pastoreio; contudo, a maior parte dos Fechos de Pasto está localizada em áreas com maior pluviosidade (e precipitações com menor irregularidade). Assim, no dia-a-dia destas comunidades a água é algo mais presente do que nos Fundos de Pasto, o que se reflete em traços diferenciadores na relação sociedade-natureza. Quanto à vegetação, há ocorrência de maior densidade (como florestas ombrófilas ou cerrado), onde predomina o rebanho bovino em relação aos caprinos e ovinos. "Normalmente, nos fechos de pasto, as áreas de uso comum são cercadas e encontram-se próximas ao sopé dos morros e aos recursos hídricos, como rios e lagoas - os refrigérios -, garantindo pastagem fresca e abundante para o rebanho que é alocado coletivamente" (SANTOS, 2010, p. 91). Diferente dos Fundos de Pasto que tem na caatinga uma reserva forrageira para todo o ano, nestas comunidades o rebanho bovino geralmente se utiliza das terras de uso comum nos períodos de estiagem.

\section{CONSIDERAÇÕES FINAIS}

Outro elemento que carece ser pontuado nesta caracterização é algo que é colocado pelos autores que discutem a questão das comunidades de Fundo de Pasto: a figura jurídica de propriedade na qual se assentam estas comunidades. Principalmente com o fim do regime de sesmarias e a instituição da Lei de Terras de 1850, consolidou-se a propriedade privada como modelo estruturado no Estado brasileiro atual. Esta mesma lei foi responsável por demarcar a formação da figura jurídica das terras devolutas.

A espacialização de boa parte das terras devolutas no estado da Bahia tem relação direta com a territorialização das comunidades de Fundo de Pasto. Muito embora sejam encontrados alguns documentos apontados como termos de partilha ou títulos de compra de terra, no âmbito do direito formal não existe titulação concreta na grande maioria das áreas destas comunidades. Isto tem sido o estopim para a maior parte dos conflitos, principalmente se for considerada a ação de alguns cartórios que são coniventes (e, por vezes, diretamente beneficiados) com os esquemas de grilagem de terras de uso comum.

As comunidades de Fundo de Pasto apresentam especificidades em suas formas de territorialização no semiárido. Estas especificidades têm sido foco de diferentes estudos no campo das ciências humanas e sociais, com destaque mais recente para a Geografia. 
Assim, para além de sua conceituação, é necessário avançar em estudos exploratórios que tragam evidência a estas comunidades, principalmente quando se compreende que analisá-las é também analisar o processo de formação dos mais distintos modos de uso da terra do semiárido brasileiro.

Quanto a formação das terras de uso comum nesta porção do estado da Bahia, percebe-se a relação dialética presente entre o processo de produção dos territórios camponeses (notadamente dos Fundos de Pasto) e o processo de produção dos territórios do latifúndio. O primeiro como complementação necessária para a sustentação do segundo, que se institui a partir de uma política de ocupação colonial, o regime de sesmarias.

\section{REFERÊNCIA}

ALCÂNTARA, D. M. de; GERMANI, G. I. Fundo de Pasto: um conceito em movimento. In: Encontro Nacional da Associação Nacional de Pós-graduação e Pesquisa em Geografia - ENANPEGE, 8, 2009, Curitiba, Anais... Curitiba, 2009.

ALCÂNTARA, D. M. de; GERMANI, G. I. As comunidades de Fundo e Fecho de Pasto na Bahia: luta na terra e suas espacializações. Revista de Geografia, Recife, $n^{\circ} 01$, v. 27, pp. 40-56, jan/abr. 2010.

ANTONIL, A. J. Cultura e opulência do Brasil. 2 ed. São Paulo: Melhoramentos; Brasília: INL, 1976.

ARTICULAÇÃO ESTADUAL DOS FUNDOS E FECHOS DE PASTO. O Fundo de Pasto que queremos. Salvador: 2003.

DIAMANTINO, P. T. "Desde o raiar da aurora o sertão tonteia": caminhos e descaminhos da trajetória sócio-jurídica das comunidades de Fundos de Pasto pelo reconhecimento de seus direitos territoriais. 2007. 143f. Dissertação (Mestrado em Direito) - Programa de Pós-Graduação em Direito da Faculdade de Direito da Universidade de Brasília, Brasília, DF, 2007.

ELIAS, D. Agronegócio e desigualdades socioespaciais. In: ELIAS, D; PEQUENO, R. (Org.). Difusão do agronegócio e novas dinâmicas socioespaciais. Fortaleza: BNB, 2006.
FERRARO JR, L. A. Entre a invenção da tradição e a imaginação da sociedade sustentável: estudo de caso dos fundos de pasto na Bahia. 2008. 484f. Tese (Doutorado em Desenvolvimento Sustentável) - Centro de Desenvolvimento Sustentável da Universidade de Brasília, Brasília, DF, 2008.

FERRARO JR, L. A.; BURSZTYN, M. À margem de quatro séculos e meio de latifúndio: razões dos Fundos de Pasto na história do Brasil e do Nordeste (1534 1982). In: Encontro Nacional da Associação Nacional de Pesquisa e Pós-graduação em Sociedade e Ambiente -ENANPPAS, 5, 2008, Brasília, Anais... Brasília, 2008.

GARCEZ, A. N. R. Fundo de Pasto: um projeto de vida sertanejo. Salvador: INTERBA/CAR, 1987.

NEVES, E. F. Sesmarias em Portugal e no Brasil. Politeia: História e Sociedade, Vitória da Conquista, Universidade Estadual do Sudoeste da Bahia (UESB), v. 1, n. 1, pp. 111-139, 2001.

NEVES, E. F. Estrutura fundiária e dinâmica mercantil: Alto Sertão da Bahia, séculos XVIII e XIX. Salvador: EDUFBA; Feira de Santana: UEFS Editora, 2005.

SABOURIN, E.; CARON, P.; SILVA, P. C. G. da. O manejo dos "Fundos de Pasto" no nordeste baiano: um exemplo de reforma agrária sustentável. Raizes, Campina Grande, UFPB, v. 18, n. 20, pp. 90-102, nov. 1999.

SANTOS, C. J. S. e. Fundo de Pasto: tecitura da resistência, rupturas e permanências no tempo-espaço desse modo de vida camponês. 2010. 290f. Tese (Doutorado em Geografia Humana) - Programa de Pós-Graduação em Geografia Humana da Faculdade de Filosofia, Letras e Ciências Humanas da Universidade de São Paulo, São Paulo, SP, 2010.

TORRES, P. R. Terra e territorialidade das áreas de fundos de pastos no semi-árido baiano - 1980-2010. 134f. Dissertação (Mestrado em Planejamento Territorial e Desenvolvimento Social) - Universidade Católica do Salvador, Salvador, BA, 2011. 